\title{
A Critical Lens on Dementia and Design in $\mathrm{HCl}$
}

\author{
Amanda Lazar \\ Northwestern University \\ Evanston, IL \\ lazar@northwestern.edu
}

\author{
Caroline Edasis \\ Mather Lifeways \\ Evanston, IL \\ cedasis@matherlifeways.com
}

\author{
Anne Marie Piper \\ Northwestern University \\ Evanston, IL \\ ampiper@northwestern.edu
}

\begin{abstract}
Designing new technologies with and for individuals with dementia is a growing topic of interest within HCI. Yet, predominant societal views contribute to the positioning of individuals with dementia as deficient and declining, and treat technology as filling a gap left by impairment. We present the perspective of critical dementia as a way of reflecting on these views in the context of recent epistemological shifts in HCI. In addition to articulating how HCI can leverage the perspective of critical dementia, we present a case analysis of technology design in art therapy involving people with dementia aimed at challenging conventional narratives. This paper calls attention to and helps solidify an agenda for how the CHI community approaches dementia, design, and technology.
\end{abstract}

\section{Author Keywords}

Dementia; design; disability; paradigm; theory.

\section{ACM Classification Keywords}

H.5.m. Information interfaces and presentation (e.g., HCI): Miscellaneous

\section{INTRODUCTION}

A growing area of HCI involves designing for the diverse lived experiences of individuals throughout the course of dementia, and in turn, understanding how to engage these individuals in research. Although awareness of dementia is growing, stigma often pervades discourse around dementia $[6,7,30]$. Some suggest that biomedical views treat people with dementia as those "whose brains have been destroyed by the disease and who therefore no longer exists as a person but only as a body to be managed" [7]. In contrast, person-centered dementia care recognizes prejudices against people with dementia and emphasizes treating people with dementia as individuals with individual preferences [13]. Post-modern views also analyze the social construction of dementia, such as society's value of shortterm rather than long-term memory [30].

Permission to make digital or hard copies of all or part of this work for personal or classroom use is granted without fee provided that copies are not made or distributed for profit or commercial advantage and that copies bear this notice and the full citation on the first page. Copyrights for components of this work owned by others than the author(s) must be honored. Abstracting with credit is permitted. To copy otherwise, or republish, to post on servers or to redistribute to lists, requires prior specific permission and/or a fee. Request permissions from Permissions@acm.org.

CHI 2017, May 06 - 11, 2017, Denver, CO, USA

Copyright is held by the owner/author(s). Publication rights licensed to ACM. ACM 978-1-4503-4655-9/17/05 ...\$15.00

DOI: http://dx.doi.org/10.1145/3025453.3025522
We refer to these emerging positions within the dementia literature as critical dementia. We argue that critical dementia takes a broad view of knowledge that considers context, embodiment, sensorial experiences, and emotion, which align with recent epistemological shifts within HCI. Specifically, HCI research has moved away from a purely cognitivist view of the mind as computer and considering computers as simply tools for work. The field now embraces the emotional, embodied, and cultural aspects of interaction with technology in everyday life, extending the scope of HCI to include a wider range of contexts and applications. Researchers have become more concerned with context, values, the situatedness of technology use and its study, and the process of meaning-making. Some have suggested that these shifts represent a new intellectual wave of research, referred to as the Third Paradigm [31,32] or Third Wave $[9,10]$ of HCI.

This vein of HCI research has begun to influence studies of computing and people with disabilities, including calls for critical analyses of technology and the experience of disability [26,50] and reflection on how assistive technology problems are defined. Further, designing to "help" can inadvertently create a power dynamic that frames people with disabilities as worse off than the researcher [65]. Recent work also cautions against problematizing aging and disability in older adulthood as something technology can solve, rather than designing for new forms of engagement and development $[12,66,76]$. However, epistemological commitments regarding cognitive impairment and design, particularly related to dementia, have received little attention.

This paper makes two contributions. First, it presents four key ways in which the critical dementia perspective resonates with recent epistemological shifts in HCI: a view of meaning-making as contextualized; physical and embodied interaction as valued forms of knowing; the importance of multisensory experiences; and embracing emotion without rationalization. Second, this paper contributes a case analysis of the design and use of technology within a context that embraces this perspective: art therapy. We articulate how art therapy applies a critical lens on dementia and how these epistemological commitments play out in practice and the design of three technology installations. In art therapy, people with dementia are positioned as capable, competent, and engaged artists who express themselves in meaningful ways. Art making is one way of engaging the perspective of people with dementia to understand how they are living 
through their social, physical, and emotional experiences [22]. We argue that the orientation of critical dementia helps us understand how HCI research positions and engages with the experience of dementia, and in turn, how technology design can provide a vehicle for challenging conventional narratives of dementia and building empathy.

\section{THE ROLE OF CRITICAL DEMENTIA IN HC}

Approximately three decades ago, researchers and practitioners began to question biomedical views of dementia - calling attention to emphases on deficits and neglect of the broader context in which people with dementia exist (e.g., sociocultural and political factors [1]). With this critique, researchers began to recognize the stigmatizing and disempowering ways that many people with dementia are treated [38], how this treatment constrains their ability to fully participate in society [3], and the discursive practices through which these messages are disseminated [29]. Some scholars articulated a postmodern view of dementia as socially constructed [30], or the notion that society creates the concept of dementia and positions it as a disease. In reaction to views that exclusively focus on loss of ability, researchers highlighted the need to understand and support the strengths of people with dementia [70].

Yet, there are ongoing debates in the dementia literature that attempt to fill some of the gaps left by particular views. While a purely social constructionist view can dissolve the notion of disability and therefore exclude painful and very real experiences of an impairment [26], person-centered dementia care makes these issues central. For instance, researchers have proposed philosophies that extend beyond Kitwood's notion of person-centered care to include the individual with dementia more fully as an equal partner in shaping dementia care [24]. Another debate concerns the way to "reclaim and reframe" the concept of 'self' in order to best position individuals with dementia (e.g., [40]). While these philosophies around critical dementia are seen as best practice, they have not yet been adopted in many of the settings in which people with dementia live [13].

We argue that the critical dementia perspective serves as a lens onto the ways people with dementia are positioned and engaged by the field of HCI. Further, it brings to light our epistemological commitments that underlie the design and evaluation of technologies involving people with dementia. Below we articulate four ways in which critical dementia aligns with recent epistemological shifts in $\mathrm{HCI}$ as a way of moving towards an agenda for research in this space.

\section{Contextualized Meaning-Making}

In contrast to viewing the mind as a computer (i.e., an information processing theoretic), scholars in HCI have begun to attend to meaning-making as a contextualized process (e.g., [70]). Similarly, critical dementia views meaning-making as contextualized and social. Rather than constraining memory to within a single individual, some dementia researchers locate cognitive processes in social and relational networks. Remembering, for people with dementia, is "played out in the everyday world... as contextual, bounded and interdependent states..." [4]. In other words, memory is not a solely individual process nor is it understandable without context. In this view, the 'loss' of an individual's memories does not result in the loss of their selfhood [5]. Furthermore, the social environment and relationships change after a diagnosis of dementia, with every expression or action of an individual with dementia being attributed to the presence of dementia rather than potentially representing an unmet need [38]. Researchers have called for the need to attend to multiple interpretations of interaction, such as a caregiver perceiving anxiety as a symptom of dementia rather than an expression of other information [69]. And, interpreting these interactions should involve "an open and unprejudiced attitude, free from tendencies to stereotype or pathologize, and meets the person with dementia in his or her uniqueness" [38].

Researchers in HCI have begun to view interactions involving people with dementia and technology in a highly interpretive, contextualized way through ethnographic design work $[21,44,77,78]$. This work examines the coordinated interaction between people with dementia and their interlocutors (e.g., therapists) as they produce creative artifacts [44] and uses technology to engage people with dementia in a dialog about social relations and one's sense of self $[77,78]$. Yet, how do researchers practically go "beyond his or her own frame of reference" [38] and see interaction and meaning-making in this way?

\section{Physical and Embodied Interaction}

Recent work in HCI emphasizes that our physical experience in the world and bodily engagement is central to interaction $[23,37,58]$ and how we construct meaning $[18,23,80]$. The perspective of critical dementia also emphasizes physical and embodied interaction. Some dementia researchers argue that Cartesian views that separate mind and body tend to value the mind more highly, and therefore position people with dementia as losing themselves or 'unbecoming' [42] as they become unable to recall memories and personal narratives [5]. In contrast, if the mind and body are seen as inseparable, selfhood can be seen as persevering through 'embodied selfhood' - the way people with dementia continue to 'be in the world' [40]. Thus we can attend to the ways that people, even with severe dementia, interact meaningfully through "the way the body moves and behaves" [40] (e.g., eye gaze, gestures, body movements [41]), even when they may not appear to engage in activities such as contemplation or reflection [40,42]. This notion of embodied selfhood recognizes that people along the spectrum of dementia continue to communicate and engage with others despite changes in cognition. As one example, people with dementia engage in turn-taking behavior in conversation even when the speech is incoherent to the other party, suggesting that this embodied act allows expression of caring towards one's interlocutor [74]. 
Researchers in HCI have begun to explore how embodied interaction with physical objects engages the perspectives of people with dementia. Morrissey et al. discuss embodied forms of participation, such as 'holding' and 'giving' and urge researchers to learn from the ways that people with dementia configure their participation, such as reading a newspaper as a way to be present but not directly involved in an activity [56]. This notion of embodied interaction leads to questions on how the ways we view 'successful' participation influences our interpretation of interaction.

\section{Experiential and Sensory Perceptions}

While early work in HCI largely viewed technology as a tool for work, recent studies embrace technology as a way of experiencing the world $[9,51]$ and seek to exploit our full range of senses [31]. Critical dementia has a similar emphasis on recognizing the ways that people along the spectrum of dementia are able to respond to and participate in sensory experiences [71]. The literature on personcentered dementia care suggests that people with dementia benefit therapeutically from sensory experiences, and encouraging engagement through stimuli is an aim of many clinical studies of dementia (e.g. [20]). To this end, researchers have studied ways to encourage sensorimotor engagement by recommending various types of activities [14,19], particularly repetitive and rhythmic experiences [47]. A therapeutic goal may be to encourage a person with advanced dementia to do "something rather than doing nothing" ([52], cited in [63]), which involves any sort of sensorial engagement with the environment. Researchers have studied the ways people with dementia engage with the environment differently than their peers: for example, with changes in short-term memory, people with dementia seem to live 'in the present moment' $[48,74]$. People with dementia have written about experiencing time differently [5] and sensory input more intensely [74].

As one way of better understanding the person with dementia's experience, HCI researchers are employing Participatory Design methods (e.g., [46,53,60]), such as soliciting feelings on and conceptions of devices for independent walking [34]. Though Participatory Design can democratize the design environment [57] and enable close contact between designers and participants, which may help foster empathy in design (suggested by [81]), it can require people with dementia to be able to verbalize their experiences in a rational way. Thus, attention is often paid to how to mitigate the impact of cognitive impairment on the design process [46], rather than taking advantage of the ways people with dementia experience, sense, and express themselves. HCI research that resonates with the perspective of critical dementia focuses on experiential and sensory perceptions in dementia and often involves the intersection of technology and the arts. For example, Morrissey and McCarthy discuss how paying attention to residents' preferences for different types of musical media can provide people with a 'way in' to connect with individuals with dementia and their experience [55]. How might we capitalize on the arts as a way of drawing out the perspectives and experiences of people with dementia?

\section{Emotion without Rationalization}

Initially, the field of HCI, growing out of Human Factors, had an orientation towards efficiency, ergonomics, and rationalization [2], which marginalized the role of emotion. Recent work in HCI, however, treats emotion and affective experience as important issues of study (see [9,31]). In fact, some scholars (e.g. [11]) view emotion as co-constructed and interpretable rather than a part of cognition that can be modeled by information flows. Critical dementia recognizes that valuing cognitive functions such as reasoning and memory above other human abilities positions people with dementia as deficient. In contrast, when emotional understanding is a valued ability, the strengths of the person with dementia become evident. For example, although a person with dementia may not recognize others such as family members or friends in a narrowly cognitive sense, they may recognize that individual as familiar and experience positive emotions associated with this recognition [74]. An individual with dementia does not need to have all the details sorted out to show caring and participate in an emotional exchange. Further, people with dementia experience the full range of human emotion $[39,49,70]$, though they may not retain the ability to express these emotions in the same ways as people who do not have dementia [5], making it difficult for others to interpret and receive these cues.

Prior work in HCI has attempted to foster emotional connections of individuals with dementia by introducing reminiscence tools aimed at revisiting past experiences (e.g., [28]). While reminiscence tools draw on the stability of long-term memory, 'successful' use of these tools may depend on a person's ability to engage rationally, connect with the past, and verbalize a response. How might new systems foster emotional connections in a way that does not require rationalization or articulation of past events?

\section{DOMAIN OF STUDY: ART THERAPY}

Drawing parallels between recent shifts in HCI and the perspective of critical dementia helps solidify a research agenda in this space, but how does the critical dementia perspective appear in practice? Recent work in HCI that is aligned with this perspective often takes advantage of the arts (e.g., music, visual arts) $[8,55,56,77,78]$. In this section, we draw on long-term field work within an art therapy program as a case of how this perspective is enacted in practice and through technology design.

\section{Method}

The study site is a residential living facility for older adults located in the Midwestern region of the United States. This community offers art therapy as a program for its residents. The majority of the adults we interacted with live in the skilled nursing portion of this community and have dementia (e.g., from Alzheimer's disease, vascular dementia from stroke) that affects their memory, speech and language, and physical abilities (e.g., limited arm/hand 
mobility, use a wheelchair). We obtained human subjects approval from the community and our University Institutional Review Board to conduct this research, as well as consent from art therapy participants and their authorized representative before studying their participation in art therapy in detail. Data was collected through over two years of weekly observations of individual and group art therapy sessions, each lasting 1.5-2 hours. In our observations, we paid close attention to how people with dementia created art and how therapists participated and responded. Over the course of this study, we interviewed eight family members and friends of art therapy participants. We also conducted in-depth interviews with 13 art therapists who work with individuals with dementia.

One naturalistic use of technology that emerged during our field work was the creation of three technology installations for an art exhibition, which occurred in the assisted living and memory care facility at our field site. The lead art therapist at our field site directed the creation and design of the three installations, and we assisted with the technical setup and maintenance during the show. We took field notes on interactions at the show and conducted interviews with therapists. We attended to how the therapists adapted and appropriated technology within this practice as well as how residents, therapists, staff, and family members negotiated its use. We also wrote reflective analytic memos of our own experiences interacting with residents and show attendees involving the technology.

Our approach to data collection and analysis is ethnographic in nature [25]. Our process of analysis emerged through interactions at our field site, with our data, and between members of our research team, one of whom is an art therapist. The regular debriefing amongst our research team was fundamental to our own adoption of the views described above as a theoretical lens. Our analytic process involved reflecting on how these views influenced our engagement in the field and interpretation of data, which include detailed field notes, audio recorded and transcribed interviews and observation sessions, and analytic memos from the research team [17].

\section{Reframing Dementia in Art Therapy}

Here, we revisit the four epistemological shifts described above in the context of our ongoing field work.

\section{Contextualized Meaning-Making}

Art making supports immersive, focused engagement while maintaining its inherently interpretive and open-ended nature. These qualities allow people with dementia to participate in creation without the expectation of a 'correct' outcome. There is no 'right way' of creating art, and the therapist configures a space in which whatever an individual does, says, or creates to express themselves is supported. In art therapy, the meaning of artwork emerges in the context of the art therapy session and includes interaction between the client and the therapist as well as the client and their artwork [15]. The role of the art therapist is not to interpret the work but rather be " $\mathrm{co}$ - creators of meaningfulness" [16]. The art therapist avoids imposing their own sense of rationality on the client and instead allows the client to narrate a reality in which the therapist will then participate. A therapist said, "You are trying to inhabit their metaphorical space. Wherever they are, whatever sort of theatrical relationship they are able to carry out, you try to participate in that..."

Art therapists construct a context in which the individual with dementia is positioned as a capable, competent, and engaged artist. One perspective in critical dementia sees this positioning coming about as a result of social personae being established and sustained through the cooperation of others (e.g., "loving parent") [69]. When individuals are seen primarily in terms of their diagnosis of dementia, others may not participate in sustaining personas aside from those associated with having dementia (e.g., "difficult patient") [69]. Here, the art therapist employs her own abilities in empathetic service of others by carefully attuning to the client's needs and providing just enough support while not over-helping [43]. Thus, the positioning of people with dementia as creative and competent artists is socially constructed through the context of art therapy.

\section{Physical and Embodied Interactions}

The perspective of embodiment treats holding a paintbrush, rubbing hands on a canvas, and manipulating art materials as forms of knowing and expressions of self which persist long into the course of dementia. Particularly for individuals with advanced dementia, the therapist attends to subtle shifts in gaze, facial expressions, and verbalizations as a way of coming alongside the individual and supporting their art making experience. To achieve this, the art therapist configures the physical space to enable and encourage clients to express themselves by simply being in the environment. This involves selecting art making tools and media that fit the individual. One therapist said, "Often times my goal with art making is to... find the right medium for the individual so they can express themselves...". The material environment is tailored to each individual, for example through propping a canvas on a client's lap, giving longer brushes and materials with less resistance (e.g., water colors) for people with limited range of motion, or introducing collaging for those who want to select and arrange existing images on a page.

Art therapists explained that any level or type of physical engagement within this context can be viewed as an expression of the self. In art therapy, simply being in the world and interacting with art materials is a positive outcome, particularly for people with severe dementia. One therapist spoke about successful art therapy sessions during which "people can line up their oil pastels and be very intentional about that and very focused, and they're manipulating the world around them, and I think that's impactful..." However, others may not see interaction in this way, such as family members who may be intent on having their relative complete a piece in a particular way. 
Art therapy is also about enabling a connection between a person's "inner world" and "outer world" by constructing a context that enables these forms of expression. One adult with dementia said, "When I'm sitting around doing nothing I can see things up here (tapping on her forehead) and I want to get them down on paper. As you can tell, I don't think, I just do it." Similarly, an art therapist described how art therapy can involve the "self coming out and landing on the page." The emerging artwork is a concrete object, which can then be spoken about and acts as a "third person" in the room. Another therapist explained that " $a$ lot of the basis of art therapy is having a space outside of one's own head to process things and deal with things." That is, embodied interaction is a critical part of the connecting between inner and outer worlds, and the traces this action leaves in the environment are viewed as expressions of the self. In other words, both the process of producing these traces and the physical byproduct of the process (i.e., the artwork) are important parts of art therapy.

\section{Experiential and Sensory Perceptions}

These embodied expressions are guided by and anchored to the physical world. As part of this, art therapists described the importance of having a tangible, external object to aid attention and engagement in the present moment. An art therapist described using three dimensional materials such as yarn and crumpled aluminum foil because these materials "bring in more information for more senses, and it's easier to pay attention." We also observed mixed media art making in which the therapist integrated fabric, needle felting, paper collage, and clay sculptures. The physicality of materials helps to orient people with dementia to the act of art making while providing rich opportunities for immersive sensory experiences.

Art therapists also discussed changing sensorial experiences occurring with dementia, such as how dementia may affect the experience of time. "The art process with people with cognitive impairment is about "now,"' said a therapist. Art making is about the interactions with materials in-the-moment. An art therapist described how this way of experiencing time affects sharing, which is a key part of the therapeutic process. For example, a person with dementia may wish to share with someone who is no longer alive. She said, "In our linear world, life and death happen, and there's no contact any more, compared to a world where we're all existing at the same time." Sharing artwork and the meaning behind it is an important way in which people connect with others [21], yet this collapsed notion of time has implications for how others perceive and interact with people with dementia.

\section{Emotion without Rationalization}

The art therapy process can elicit intense emotional experiences. One therapist explained, "sometimes that experience making the art is crying. Sometimes the experience of making the art is belly laughing." Emotions such as anxiety or sadness are sometimes attributed to the presence of dementia rather than valid reactions to an event or situation, but art making and sharing provides a way for these emotions to be taken seriously and received by others. A therapist described art therapy as supporting:

"The ability to express yourself and what's important to you or what you're feeling regardless of your verbal ability... through art materials or through your behavior. Me being able to view somebody's expression as an expression of who they are as a person and not just as a negative symptom of a disease."

This externalization of emotion provides an artifact that validates one's own expressions and enables connecting with others. As one adult with dementia commented, "My artwork says that I like to see people smile. I didn't draw anybody fighting or screaming at each other." Often when making art "you are just in your head about it," explained a therapist, but the concrete nature of the artwork also plays a role in sharing these expressions with others. This therapist continued, "So showing that [artwork] to somebody else kind of makes you realize that it's like a real thing or it exists for other people too, not just you in your mind..." The externalization of emotions through art can also help others take an individual's expressions seriously:

"I think the urge is so common if there are any negative emotions to sort of want to protect the person with dementia, and be like 'no, no, no, you're fine'... If you are faced with a painting of [a] tornado, or... a huge painting and just one person in the corner...you couldn't...see that and say 'oh you're fine.' It's like 'oh no, that's you sitting in the dark by yourself'... it makes it harder to ignore."

Art therapists are skilled at eliciting and contextualizing these expressions, but many other people in an individual with dementia's life have yet to embrace a view that enables understanding behavior in this way.

\section{Reframing Dementia through Interactive Technology}

Art therapists are aware of how dementia is perceived in society and seek ways to reframe dementia for others, including family members of people with dementia, friends, caregivers, and community staff. One way of challenging dominant views of dementia is by organizing art exhibitions that allow others to engage with creative expressions generated through therapy. In this section, we describe the design of three technology exhibits aimed at providing a critical lens on dementia, or as the lead therapist said, "helping others see residents in a new way."

\section{An Invitation to Engage in Empathetic Art Making}

Diane seems to enjoy the sensory and kinesthetic experience of art therapy, often becoming relaxed and engaged when interacting with art materials and spreading paint on a canvas. Diane has advanced dementia, impacting her memory, communication, and motor ability. Her speech is severely limited, and she rarely talks in sentences that others can understand. It appears that Diane derives far more benefit from the interactions during therapy than having a final product of artwork that she produces, as she 


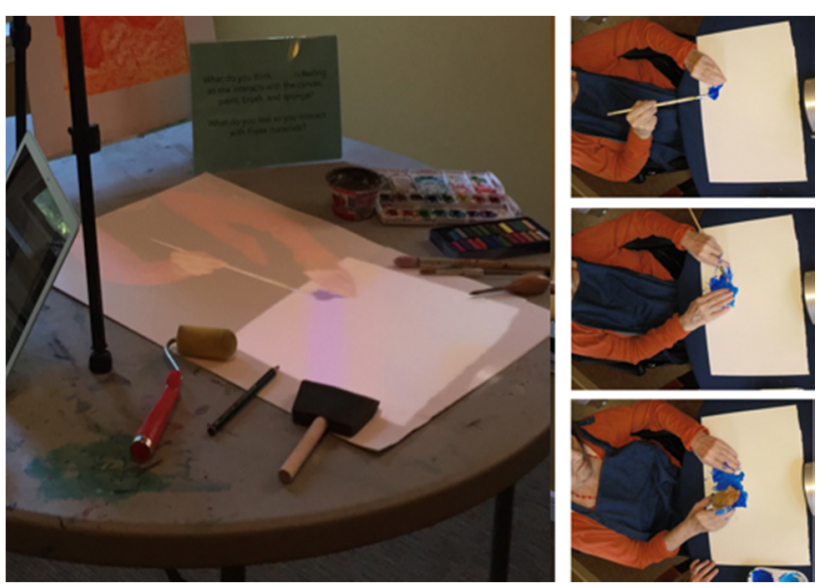

Figure 1. Left: Images of Diane making art are played in sequence and projected onto the art studio table. Right: Example images captured during therapy session.

does not seem to recognize or connect with her artwork after it is made. The therapist wanted to design an exhibit that would showcase Diane's process of creation.

Working with Diane's therapist, we captured Diane making art by placing a GoPro camera (capturing two images per second) over the art studio table. We converted the images into a time-lapsed one-minute video and projected it onto the same art making space (Figure 1). The therapist placed art materials that Diane uses regularly alongside the projected image, such as a paintbrush with a large round handle, watercolors, and an apron. The therapist projected the video onto a stack of paper as a way of inviting people to paint alongside the projection of Diane painting. A sign accompanying the exhibit asked visitors "What do you think Diane is feeling as she interacts with the canvas, paint, brush, and sponge? What do you feel as you interact with these materials?"

The therapist explained that people do not see Diane's abilities and that this exhibit was designed to convey her abilities and engagement during therapy, as Diane "can't really communicate verbally and doesn't move much... This is to help you understand how those images [paintings] are made." The therapist said that many people are not comfortable interacting with or making art with someone with advanced dementia. She reflected on taking Diane to the independent living common area for an event:

“... as we wheeled in I remember everybody looking and being like 'Oh look at Diane, look how much she's changed, '... like that muffled behind your hand gossiping of 'look at what's happened to this person.",

The therapist was aware that there was a risk of people seeing the exhibit and having a similar reaction but that this time visitors are "entering her space." She explained:

"The fact that they're coming in to the space of the people that have made the art, they're entering their world.... the privileged group very rarely has to enter the context of whatever the underprivileged group is... Just by entering that physical space, it changes the conversation and the emotional impact of connecting with what they've created... You're seeing the world through their eyes rather than us coming down to the first floor in all its fanciness and its social norms."

The "first floor" is where individuals in independent living reside. Visitors to the exhibit, including first floor residents, came into the art therapy space, with its own values and culture. Visitors needed to take on new ways of understanding to make sense of and exist in this space, rather than expecting others to conform to the norms in the spaces where they felt comfortable. Nearly 100 people came to the art show and viewed the projected images of Diane painting in the studio. Yet, Diane herself was one of the first people to interact in the space. Her caregiver pushed her wheelchair up to the table and Diane seemed to instinctively, without hesitation, reach for the materials on the table. An observing therapist dipped a paintbrush in paint and put the brush in Diane's hand. She began to paint. Though Diane does not appear to recognize the art she has made or appear able to follow verbal instructions to begin painting, the contextual cues of the room and setup, combined with her past experiences of art making, led her to instinctively engage in painting without prompting.

Diane's daughter visited the exhibit and said, "It's beautiful, seeing it from this perspective. There is a tenderness. You can see the focus... Just from her hands..." Many staff and residents also viewed Diane's exhibit, and residents were struck by seeing someone, who they viewed as unable to make art, actively painting and engaged in this way. One resident said in disbelief, "I try to talk to her but she can't respond at all, but she can do that. It's amazing." The therapist relayed a comment from a resident who said "Diane used to live on my floor. When I tried to visit her, she couldn't talk anymore. I would never believe that she could do this." The exhibit was emotional for some, yielding both positive emotions as well as emotions stemming from a sense of loss. The therapist said that visitors told each other "that's the room you go into if you want to cry." One staff member who knew Diane well began to cry when she saw the images playing. She explained that observing the changes in Diane and seeing what she is doing in art therapy is very emotional.

Though Diane rarely speaks, the projection of Diane physically interacting with materials as she created her artwork led to the artwork being regarded as an expression of self. A staff member commented, "It is interesting, this is her expression." This echoes reflections on how the art acts as a vehicle for communication due to the expressive nature of the physical materials used [22]. One researcher has written that when she has made art alongside others, the "color and texture has been the language and the paper has formed the meeting place. The tone and pressure of the marks have in fact been the expression of the emotions" [22]. The projection inviting visitors to sit alongside Diane both presents a record of this communication that took 

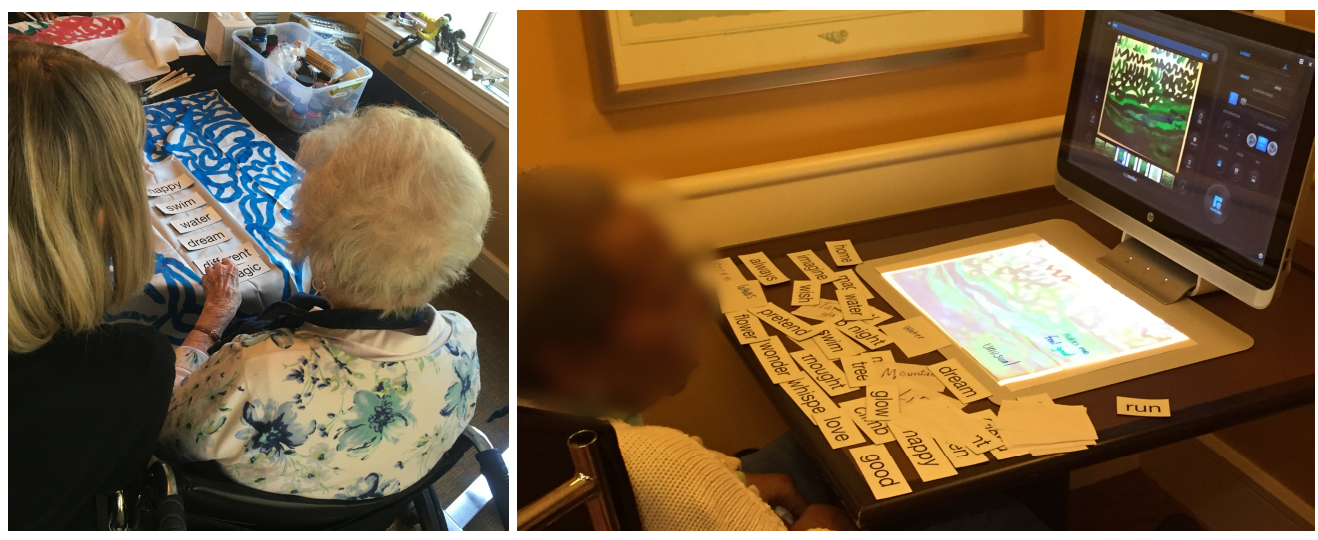

Figure 2. Left: Lee uses word tiles to describe her artwork (painting on silk). Right: Gallery visitors respond to Lee's artwork by arranging word tiles and capturing an image with an HP Sprout. arranged word tiles on artwork that was projected on the space in front of the computer and then captured an image of their arrangement as a response to Lee's paintings. After the show, Lee viewed the visitor's responses. This installation created a dialogic space - or opened up possibilities for alternate views of dementia to be "held together in the creative tension of a dialog" [79]. place with the art therapist - a testament to Diane's ability to express herself - and invites the visitor to empathetically take part in an interaction that took place with Diane.

The therapist, reflecting with other staff after the show, described how inviting people to make art with the projection of an image, rather than the presence of the individual in the projection, allows people to interact only with the visual aspects instead of confronting the entire physical reality of a person with advanced dementia (e.g., smells, sounds, physical contact). She explained:

"We've been talking about changing the perceptions of dementia so that it's not this old-fashioned idea of people losing their identity and just becoming blank ghosts of their former self... seeing the projection of somebody's hands [is] a step towards doing that, to see them in the act of making, and then to be able to interact with that in a way that's much less scary than interacting with the person directly, but still feels very intimate."

Diane's therapist described how getting residents and staff comfortable with interacting with the projection - many of whom appeared hesitant to do so during the exhibit - could be the first step in breaking down stigma around cognitive impairment, offering a therapeutic goal in and of itself.

\section{Creating an Engaging and Accessible Dialogic Space}

Lee can understand written and spoken language and express herself through art, though she is unable to form coherent sentences or write. Lee had a stroke several years ago and as a result has vascular dementia, which affects her short-term memory and expressive language. During the course of our study, the therapist began providing Lee with printed word tiles that she can manipulate and arrange alongside her artwork as a way of describing and titling her work (see Figure 2). Given that this form of expression works well for Lee, the therapist created an interactive exhibit for Lee's work that invited gallery visitors to respond to several of her art pieces using the same word tiles. The exhibit used an HP Sprout computer, which is a desktop computer that projects onto and captures images of the physical space in front of the computer. Gallery visitors
Lee's communication occurred through both the art and the word tiles, and many visitors to the installation reacted to Lee's artwork using the Sprout. Lee's family and friends were excited to know that she was communicating through the tiles, as she had refused other communication aids in the past. Looking at Lee's artwork and word tiles, one resident from independent living said, "this is very important to me. I knew her before her stroke and this is how she's expressing herself. I see her in the hall and she smiles. I know she knows me." For this resident, though she was aware that Lee recognized her, she felt unable to confirm that connection without verbal communication from Lee. She was excited by the potential of interacting with Lee through the word tiles. The therapist explained:

"It's about communication that runs both ways. Where she's communicated something and then the audience is invited to communicate back and it's all through her form of expression... in normal day-to-day interactions we set the terms of communication based upon what we expect is typical, and she can't fit into that. So she is kicked out of normal interaction. But when she's communicating through her artwork and through the tiles, that's how she's chosen to communicate and so then people are responding back that way... We're just changing to her discourse."

One of Lee's family members described how important it was for Lee to receive feedback from viewers, explaining that "my mom can't talk and express her feelings but she can still read, so she's able to pull out- to use words to describe what she's thinking... other people could put their same feelings so she could see that."

Although designed around Lee's experience, this mixedmedia space invited interaction by other visitors with cognitive impairments. For example, one resident with severe dementia and her daughter sat next to each other and placed words on the projection. Whether or not the resident understood exactly what was taking place in a narrowly cognitive sense was not important, as the interaction invited her to generate an expression by arranging physical objects, sitting alongside a loved one and engaging in a parallel 
activity, and reacting to words rather than needing to generate them. We also observed individuals with dementia contributing new words to the exhibit. One visitor with dementia who speaks quietly and is not often heard in larger conversations added the words "makes me feel good," which was written on a blank tile. Several visitors, including those from independent living and staff, re-used this resident's words. This dialogic space allows for remixing and re-appropriating other people's language, including the voices of individuals who are often not heard or valued by others in society.

\section{Contextualizing Artwork with Voice}

Clara is able to express herself verbally and through writing. She has Parkinson's disease that affects her mobility and cognition. She previously played piano professionally and would often play in common areas of her residential community. With the progression of Parkinson's disease, she is no longer able to play as she used to. The art therapist explained:

"Hearing her music from the past is painful because she cannot do it any longer and is reminded of that, so we don't like to do it [listen to it], but if you can bring that past into the present in a positive way, that can be very healing."

The therapist has been exploring ways to connect prior recordings of Clara playing music with her current artwork as this can help Clara reconnect with this part of herself in a way that "combines what she was able to do in the past with what she can do now." The therapist began using Livescribe Smarten Sound Stickers [82] to achieve this. With the therapist facilitating, Clara attached recordings of her playing music in the past and new recordings of poetry and descriptions she composed to accompany her artwork.

The therapist displayed Clara's collection of interactive artwork at the art exhibition (Figure 3). Visitors could use the digital pen to tap on the interactive stickers and hear Clara's prerecorded audio. Clara described how playing the piano had a "performing aspect to it and that's what I really liked." This installation enabled Clara to rehearse and craft a refined audio for each visual image, and she explained that her audio could be heard "again and again." In rehearsing and pre-recording her audio, Clara effectively transmitted her message in a way that surprised and impressed viewers of the exhibit. The therapist explained:

"[Visitors] were shocked I think to realize it was her speaking directly to them, and speaking with such confidence. I think because... she was in her zone and safe, was able to say what she wanted to say and be heard in the way that she wanted to be heard, and so I think that is different from how people normally hear her... for her to be the empowered one here and be able to communicate what she wants to communicate, and I definitely saw people pause and experience that engagement."

Clara herself said, "to see it hanging up there with music that I'd chosen to go with it was very powerful... It seemed

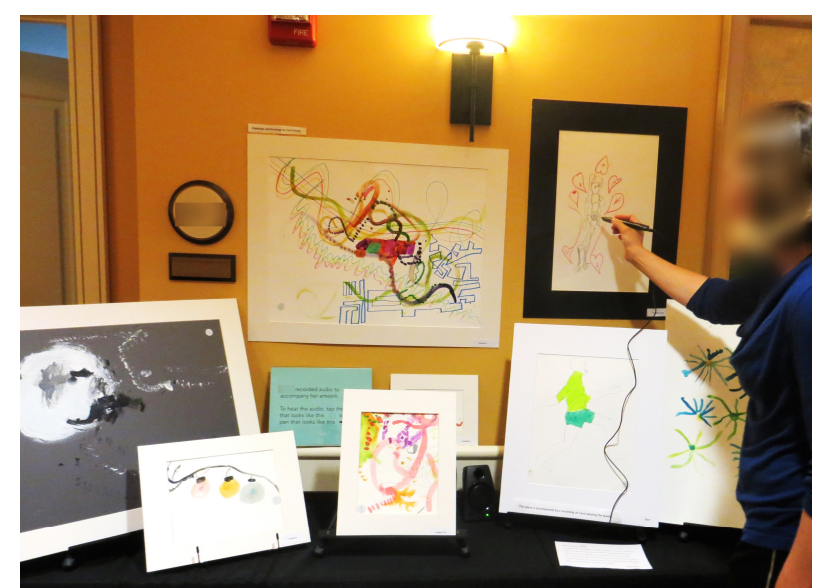

Figure 3. Therapist and resident used Livescribe Smartpen Sound Stickers to attach audio recordings to artwork. Tapping the pen on artwork plays an audio caption or accompanying music.

like it was alive because the music was alive." This exhibit provided viewers with a way to interact with her artwork and expressions in a way that she herself could shape and contextualize through the audio she added. We observed one visitor saying to Clara "this is beautiful-I love hearing what you have to say." Additionally, like Diane's exhibit, viewers who might not feel comfortable interacting directly with Clara could interact with her expressions through the exhibit. Clara's therapist said:

“...when they come into the care venue typically they might not know how to interact. And so then they are given these tools that invite them to interact with this artwork... People were so amazed to hear her voice and reflect on what her voice sounded like and what she was saying, and they would comment on her comments and say 'that's very moving' or 'oh what a beautiful voice she has' or 'oh I didn't know she played music like that'."

This installation provided visitors with 'tools' to begin interactions with people with cognitive impairments through their body of work. The interactive artwork provided a conversation piece to engage alongside Clara. Seeing Clara's artwork, contextualized with her own comments and selected media, led some of these visitors to be able to 'see past' external factors that they had found intimidating or off-putting and be able to see some of her other characteristics, such as her pleasing voice, ability to express emotions in a moving way, and musical talent.

\section{Changing Perceptions of Dementia}

These three technology installations were situated within the larger art exhibition located on this community's fifth floor. The fifth floor itself has a negative stigma within this community, yet the therapist viewed the exhibit as "changing the definition of what it means to come to [fifth] floor. People think you come to the [fifth] floor and you die, but you come to be an artist." The therapist further explained the impact of the exhibit on visitors: 
"They're understanding that these people are here, they're creative, they're present, that they have personality and have something to say and something to offer and are still unique individuals, which we take for granted working up here, but the majority of cognitively normal people... really don't talk about them or think about them that way."

Similarly, a resident visiting from independent living said, "these are people with problems and to generate all this work is incredible." While the comments seem affirming, the idea of "people with problems" neglects the lived experience of dementia, emphasizes differences, and sensationalizes the work, perhaps akin to outsider art [62]. Nonetheless, as several therapists discussed, the exhibit "transformed" the fifth floor space from somewhere unwelcoming and even "scary" to somewhere accessible, inviting, and where creative expressions are cultivated.

Beyond this exhibit, art therapists continuously engage in advocating for critical dementia and translating between different ways of viewing dementia. Care staff often misinterpret the art therapy process as "arts and crafts" rather than as a form of meaningful emotional and artistic expression; family members may encourage an adult to make art about a shared memory when the adult has other needs to express. Art therapists also translate between these worldviews during care plan meetings - they convey the creativity, engagement, and self-expression observed during art making to physicians, nurses, and staff who largely approach care through a biomedical view. As echoed by these therapists, caregivers "recreate dementia and dementia care" through their daily practices, which are based in part on the constructs that are embedded in traditional approaches to care work, such as 'doing to' rather than 'doing with' a care recipient [61]. Therapists in our study saw a significant gap between the critical dementia perspective and the application of this view in care settings, and they saw technology design and research as able to play a crucial role in advancing this agenda.

\section{DISCUSSION}

We have highlighted how the perspective of critical dementia resonates with recent epistemological shifts in $\mathrm{HCI}$ and have provided an example of this perspective in practice. We argue that critical dementia provides a lens on understanding technology design and use, and in turn, the field of HCI is well-positioned to advance this perspective through application of technology. Similar analyses take a critical view on aging (e.g., $[45,76])$ and establish positions consistent with social and critical gerontology [76], which attends to the ways that cultural, scientific, and economic practices contribute to the positioning and oppression of older adults [54,67]. Collectively, this work is helping solidify an agenda on aging, and we expand this agenda to consider the positioning of dementia in HCI.

\section{Considerations for Research}

The critical dementia perspective offers three important considerations for HCI research. First, it encourages researchers to examine what it means to 'be in the world' through whatever terms the individual brings to the interaction. That is, we no longer focus on what an individual can or cannot do; the focus shifts to what an individual actually does and interpreting the contextualized meaning of these actions. This inherently shifts the focus of analysis to the pragmatics of interaction and what is made out of that particular moment. Thus, we may look at how an individual interacts with the art materials that are laid out in front of them, whether this involves using these materials to paint or lining them up in their workspace as a way of expressing an underlying need or desire. We must be mindful of how our values and perspectives influence analyses of interaction (e.g., treating painting as 'more engaged' than the act of lining up materials). We must also reconsider what constitutes 'successful' engagement as well as how we assess effective use of technology resources we introduce into the field. As in other contexts, the involvement of skilled 'interpreters' (e.g. therapists), who are mindful of these complexities, is invaluable [35].

Second, the acceptance of embodiment as a way of understanding interaction stands to enhance how we interpret the actions of people with dementia, who are then no longer seen as lacking but rather as having strengths to contribute to the complex ecosystem of interactions. Bringing the notion of embodied interaction to the center of our research agenda can empower individuals with dementia, yet this requires attending to embodied forms of knowing and adapting our practices to foreground these experiences $[40,56]$. Methodologies that focus on action and bodily movement (e.g., ethnomethodology, interaction analysis) are especially relevant (as called for by [23]). Further, a macro-view of enjoyment, for example, may need to be unpacked through micro-level analyses of bodily interaction (e.g., eye gaze, gestures, body position, tone of voice, breathing rate, etc.), which can reveal subtle cues that indicate relaxation, comfort, or familiarity with a person or object (as done in dementia studies, such as [64]). Attending to bodily rhythms in this way aligns with somaesthetic appreciation design [36].

Third, this perspective challenges how we involve people in research, which is a topic of debate in HCI more broadly [75]. The notion of citizenship recognizes that people with dementia are often treated in disempowering ways that prevent them from participating in society to the full extent possible [3]. The extent to which we, as researchers, conceive of individuals with dementia as able to take part in research or design work determines the opportunities for individuals with dementia to reveal, explore, and develop themselves through this process. While prior work articulates strategies for involving individuals with cognitive impairments in design [46], a critical perspective would avoid positioning cognitive impairment as something to "mitigate" in the design process. Rather, a critical perspective pushes the boundaries of what constitutes participation and explores how diverse physical, sensorial, and emotional experiences opportunistically 
emerge and provide a way forward in design (as in [56]). Interactions between people with and without dementia could be supported by shifting dialogue towards a reality that individuals with and without dementia can jointly inhabit, for example through activities such as joint poetry creation which allows for fluid interaction rather than rigid conversational rules. With a view of technology that aims to see and understand, rather than getting participants to follow directives or achieve a particular end state, people along the spectrum of dementia can participate in full.

\section{Inspiring Design Directions}

A critical lens on dementia also inspires new directions for designing technologies to support the full range of experiences of living with dementia. As one example with respect to the changing sensory experience of dementia, people seem to experience time in a non-typical way (i.e., living in the present) $[5,48,74]$. We should reflect on the way we view the concept of time and instantiate it in the design and evaluation of technologies for people with dementia. Future work could look into systems that do not impose a temporal ordering on people who do not experience it, such as digital photo books that continuously loop. Further, technology can open up new possibilities for sharing beyond the here and now to include people throughout an individual's life, including deceased relatives. Though a biomedical view characterizes perceptions of interacting with people who are no longer alive as a negative symptom of dementia, for some people with dementia, these can be pleasurable interactions [55] and, in some cultures, may be respected as interactions with the supernatural $[33,59]$. A promising research direction involves the design of digital spaces where artifacts and stories can be shared with the deceased and revisited.

One value in design that should be reconsidered in the context of dementia is the notion of reminiscence or connecting emotionally with the past in the present moment. While people with dementia richly experience emotions, tensions may arise due to the temporal and ephemeral nature of interactions. Family members may feel frustrated when they spent pleasant hours with a relative with dementia and the relative does not appear to recall details of the event afterwards. However, the affect and behavior of people with dementia do change after experiences such as family visits, even when an individual cannot recall or verbalize memories or information - what is accessed is implicit, but not explicit memories [68,72]. With this perspective, a potential 'memory support' could be oriented towards the family member, helping reaffirm that the emotional exchange has still taken place and that their relative is in a better mood than they had been before. Indeed, one role of technology may be to facilitate a sense of purpose beyond the visit [77], which may involve supporting the persistence of an emotional connection that others desire.

Technology design itself can also challenge conventional narratives of dementia. A diagnosis of cognitive impairment often results in stigma [27] from even wellmeaning staff, family members, people living in the same community, and researchers. This stigma often relies on an interpretation of changes experienced through the course of dementia as eroding an individual's personhood, leaving people that exist "only as a body to be managed" [7] rather than individuals who continue to sense, emote, and exist in the world. And, it is important to recognize that people with dementia may prize cognitive abilities, wish to exercise them, and grieve or become frustrated as they change. Though changing an entire culture of how we relate to cognitive impairment is not feasible, technology design can focus on building 'a way in' for others to interact and empathize with a person with dementia's individual experience. In our work, technology helped facilitate this empathizing - interactive exhibits were configured to provide a structured but less intimidating way to interact while offering a glimpse into a person's lifeworld. One open research area involves designing technologies to foster interaction, understanding, and empathy between people with diverse cognitive abilities.

\section{CONCLUSION}

The perspective of critical dementia and its synergies with recent epistemological shifts in the field of HCI helps provide an agenda for research and design in this space. Our work and that of others demonstrates that the arts provide a fruitful domain of study $[44,55,56,77,78]$. A focus on the arts, specifically arts-based therapies, enables researchers to draw on the experience of people who have been trained to attune themselves to the voices of individuals with dementia (e.g., therapists) as a way of understanding interaction. Learning from the domain of art therapy, we observe that creativity, engagement, and rich emotional expression emerge through this way of looking at interaction, offering both a more empowering stance for people with dementia and a way of engaging their perspective. Further, technology design can be a vehicle for challenging and reflecting on societal views of dementia. Rather than prescribing solutions, researchers can view their role as offering tailored technology in ongoing dialogue with those in the space. Yet, as a community, we must be mindful of how our technology design practices reaffirm certain values and positions towards dementia.

\section{ACKNOWLEDGEMENTS}

This work was supported in part by NSF grant IIS1551574. We thank the individuals who participated in this study and Jim Hollan for feedback on an early version of this paper.

\section{REFERENCES}

1. Trevor Adams. 1996. Kitwood's approach to dementia and dementia care: a critical but appreciative review. Journal of advanced nursing 23, 5: 948-953.

2. Liam J Bannon. 1991. From Human Factors to Human Actors: The Role of Psychology and Human-Computer Interaction Studies in Systems 
Design. In Design at work: Cooperative Design of Computer Systems., Joan Greenbaum and Morten Kyng (eds.). Lawrence Erlbaum Associates, Inc., 25-44.

3. Ruth Bartlett and Deborah O'Connor. 2007. From personhood to citizenship: Broadening the lens for dementia practice and research. Journal of Aging Studies 21, 2: 107-118. http://doi.org/10.1016/j.jaging.2006.09.002

4. Raewyn Bassett and Janice E. Graham. 2007. Memorabilities: enduring relationships, memories and abilities in dementia. Ageing and Society 27, 4: 533. http://doi.org/10.1017/S0144686X07005971

5. Anne Davis Basting. 2003. Looking back from loss: Views of the self in Alzheimer's disease. Journal of Aging Studies 17, 1: 87-99. http://doi.org/10.1016/S0890-4065(02)00092-0

6. Renée L. Beard, Jenny Knauss, and Don Moyer. 2009. Managing disability and enjoying life: How we reframe dementia through personal narratives. Journal of Aging Studies 23, 4: 227-235. http://doi.org/10.1016/j.jaging.2008.01.002

7. Susan M. Behuniak. 2011. The living dead? The construction of people with Alzheimer's disease as zombies. Ageing and Society 31, 1: 70-92. http://doi.org/10.1017/S0144686X10000693

8. Mark Blythe, Peter Wright, John Bowers, et al. 2010. Age and experience: ludic engagement in a residential care setting. Proceedings of the 8 th ACM Conference on Designing Interactive Systems (DIS '10): 161-170.

http://doi.org/10.1145/1858171.1858200

9. Susanne Bødker. 2006. When second wave HCI meets third wave challenges. Proceedings of the 4th Nordic conference on Human-computer interaction: changing roles (NordiCHI '06), ACM Press, 1-8.

http://doi.org/10.1145/1182475.1182476

10. Susanne Bødker. 2015. Third-wave HCI, 10 years later---participation and sharing. interactions 22, 5: 24-31. http://doi.org/10.1145/2804405

11. Kirsten Boehner, Rogério DePaula, Paul Dourish, and Phoebe Sengers. 2005. Affect: From Information to Interaction. Proceedings of the 4th decennial conference on Critical computing: between sense and sensibility (CC '05), ACM Press, 59-68. http://doi.org/10.1145/1094562.1094570

12. Robin Brewer and Anne Marie Piper. 2016. "Tell It Like It Really Is": A Case of Online Content Creation and Sharing Among Older Adult Bloggers. Proceedings of the 2016 CHI Conference on Human Factors in Computing Systems (CHI '16), ACM Press, 5529-5542.

http://doi.org/http://dx.doi.org/10.1145/2858036.28 58379
13. Dawn Brooker. 2003. What is person-centred care in dementia? Reviews in Clinical Gerontology 13, 3: $215-222$.

http://doi.org/10.1017/S095925980400108X

14. Linda L. Buettner. 1999. Simple Pleasures: A multilevel sensorimotor intervention for nursing home residents with dementia. American Journal of Alzheimer's Disease and Other Dementias 14, 1: 41-52.

http://doi.org/10.1177/153331759901400103

15. Helene Burt. 2012. Art Therapy and Postmodernism: Creative Healing Through a Prism. Jessica Kingsley Publishers, London.

16. Peter Byrne. 1995. From the depths to the surface: Art therapy as a discursive practice in the postmodern era. The Arts in Psychotherapy 22, 3: 235239.

17. Kathy Charmaz. 2014. Constructing Grounded Theory. Sage Publications, London.

18. Andy Clark. 2008. Supersizing the Mind: Embodiment, Action, and Cognitive Extension. Oxford University Press.

19. Jiska Cohen-Mansfield, Marcia S. Marx, Maha Dakheel-Ali, Natalie G. Regier, and Khin Thein. 2010. Can Persons With Dementia Be Engaged With Stimuli? American Journal of Geriatric Psychiatry 18, 4: 351-362. http://doi.org/10.1097/JGP.0b013e3181c531fd

20. Jiska Cohen-Mansfield, Marcia S Marx, Khin Thein, and Maha Dakheel-Ali. 2010. The impact of past and present preferences on stimulus engagement in nursing home residents with dementia. Aging \& mental health 14, 1: 67-73. http://doi.org/10.1080/13607860902845574

21. Raymundo Cornejo, Robin Brewer, Caroline Edasis, and Anne Marie Piper. 2016. Vulnerability, Sharing, and Privacy: Analyzing Art Therapy for Older Adults with Dementia. Proceedings of the 19th ACM Conference on Computer-Supported Cooperative Work \& Social Computing (CSCW '16), ACM Press, 1572-1583.

22. Claire Craig. 2004. Reaching Out with the Arts: Meeting with the Person with Dementia. In Dementia and Social Inclusion: Marginalised groups and marginalised areas of dementia research, care and practice, Anthea Innes and Carole Archibald (eds.). Jessica Kingsley Publishers, 184-198.

23. Paul Dourish. 2001. Where the Action is: The Foundations of Embodied Interaction. MIT Press.

24. Sherry L. Dupuis, Jennifer Gillies, Jennifer Carson, et al. 2011. Moving beyond patient and client approaches: Mobilizing "authentic partnerships" in dementia care, support and services. Dementia 11, 4: 427-452.

http://doi.org/10.1177/1471301211421063

25. Robert M. Emerson, Rachel I. Fretz, and Linda L. 
Shaw. 2011. Writing Ethnographic Fieldnotes. University of Chicago Press.

26. Christopher Frauenberger. 2015. Disability and Technology: A Critical Realist Perspective. Proceedings of the 17th International ACM SIGACCESS Conference on Computers \& Accessibility (ASSETS '15), ACM Press, 89-96. http://doi.org/10.1145/2700648.2809851

27. Linda Garand, Jennifer H Lingler, Kyaien O Conner, and Mary Amanda Dew. 2009. Diagnostic Labels, Stigma, and Participation in Research Related to Dementia and Mild Cognitive Impairment. Research in Gerontological Nursing 2, 2: $112-122$.

28. Gary Gowans, Jim Campbell, Norm Alm, Richard Dye, Arlene Astell, and Maggie Ellis. 2004. Designing a Multimedia Conversation Aid for Reminiscence Therapy in Dementia Care Environments. Extended Abstracts on Human Factors in Computing Systems (CHI EA '04), ACM Press, 825-836. http://doi.org/10.1145/985921.985943

29. Jacqueline A. Guendouzi and Nicole Müller. 2012. Critical approaches to discourse. In Approaches to discourse in dementia. Psychology Press, 141-167.

30. Nancy Harding and Colin Palfrey. 1997. The Social Construction of Dementia: Confused Professionals? Jessica Kingsley Publishers.

31. Steve Harrison, Phoebe Sengers, and Deborah Tatar. 2011. Making epistemological trouble: Third-paradigm HCI as successor science. Interacting with Computers 23, 5: 385-392. http://doi.org/10.1016/j.intcom.2011.03.005

32. Steve Harrison, Deborah Tatar, and Phoebe Sengers. 2007. The three paradigms of HCI. Proceedings of alt.chi, CHI '07, 1-18. http://doi.org/10.1234/12345678

33. J Neil Henderson and John W Traphagan. 2005. Cultural Factors in Dementia. Alzheimer Disease \& Associated Disorders 19, 4: 272-274. http://doi.org/10.1097/01.wad.0000190806.13126.5 5

34. Kristine Holbø, Silje Bøthun, and Yngve Dahl. 2013. Safe Walking Technology for People with Dementia: What Do They Want? Proceedings of the 15th International ACM SIGACCESS Conference on Computers and Accessibility (ASSETS '13), ACM Press. http://doi.org/10.1145/2513383.2513434

35. Jonathan Hook, Rachel Clarke, John McCarthy, Kate Anderson, Jane Dudman, and Peter Wright. 2015. Making the Invisible Visible: Design to Support the Documentation of Participatory Arts Experiences. Proceedings of the 33rd Annual ACM Conference on Human Factors in Computing Systems (CHI '15): 2583-2592. http://doi.org/10.1145/2702123.2702187

36. Kristina Höök, Martin P Jonsson, Anna Ståhl, and Johanna Mercurio. 2016. Somaesthetic Appreciation Design. Proceedings of the 2016 CHI Conference on Human Factors in Computing Systems (CHI'16): 3131-3142. http://doi.org/10.1145/2858036.2858583

37. Edwin Hutchins. 1995. Cognition in the Wild. MIT Press.

38. Tom Kitwood. 1997. Dementia Reconsidered: the person comes first. Open University Press, Buckingham.

39. Ann M Kolanowski, Mark S Litaker, and Patricia A Catalano. 2002. Emotional Well-Being in a Person With Dementia. Western Journal of Nursing Research 24, 1: 28-48.

40. P. C. Kontos. 2005. Embodied selfhood in Alzheimer's disease: Rethinking person-centred care. Dementia 4, 4: 553-570. http://doi.org/10.1177/1471301205058311

41. P. C. Kontos. 2012. Rethinking sociability in longterm care: An embodied dimension of selfhood. Dementia 11, 3: 324-346.

http://doi.org/10.1177/1471301211421073

42. Pia C. Kontos. 2004. Ethnographic reflections on selfhood, embodiment and Alzheimer's disease. Ageing and Society 24, 6: 829-849. http://doi.org/10.1017/S0144686X04002375

43. Edith Kramer. 2000. The Art Therapist's Third Hand: Reflections on Art, Art Therapy and Society at Large. In Art As Therapy: Collected Papers. Jessica Kingsley Publishers, 47-70.

44. Amanda Lazar, Raymundo Cornejo, Caroline Edasis, and Anne Marie Piper. 2016. Designing for the Third Hand: Empowering Older Adults with Cognitive Impairments through Creating and Sharing. Proceedings of the 2016 ACM Conference on Designing Interactive Systems (DIS '16), 10471058.

45. Ann Light, Tuck W. Leong, and Toni Robertson. 2015. Ageing Well with CSCW. Proceedings of the 14th European Conference on Computer Supported Cooperative Work (ECSCW 2015), 19-23. http://doi.org/10.1007/978-3-319-20499-4

46. Stephen Lindsay, Daniel Jackson, Cas Ladha, Karim Ladha, Katie Brittain, and Patrick Olivier. 2012. Empathy, participatory design and people with dementia. Proceedings of the SIGCHI Conference on Human Factors in Computing Systems (CHI '12), ACM Press, 521-530. http://doi.org/10.1145/2207676.2207749

47. Nancy L. Mace. 1987. Principles of activities for persons with dementia. Physical \& Occupational Therapy in Geriatrics 5, 3: 13-27. http://doi.org/http://dx.doi.org/10.1300/J148v05n03 03

48. $\quad \bar{S}$ arah MacPherson, Michael Bird, Katrina 
Anderson, Terri Davis, and Annaliese Blair. 2009. An art gallery access programme for people with dementia: "you do it for the moment". Aging \& Mental health 13, 5: 744-752. http://doi.org/10.1080/13607860902918207

49. Carol Magai, Carl Cohen, David Gomberg, Chris Malatesta, and Clayton Culver. 1996. Emotional expression during mid- to late-stage dementia. International psychogeriatrics 8, 3: 383-395. http://doi.org/10.1017/S104161029600275X

50. Jennifer Mankoff, Gillian R. Hayes, and Devva Kasnitz. 2010. Disability studies as a source of critical inquiry for the field of assistive technology. Proceedings of the 12th international ACM SIGACCESS conference on Computers and accessibility (ASSETS '10), ACM Press, 3-10. http://doi.org/10.1145/1878803.1878807

51. John McCarthy and Peter Wright. 2004. Technology as Experience. Interactions 11, 5: 4243. http://doi.org/10.1109/TPC.2005.859719

52. M McFadyen. 1984. The measurement of engagement in the institutionalized elderly. In Psychological approaches to the care of the elderly, I Hanley and J Hodje (eds.). Croom Helm, London.

53. Franka Meiland, Rose-Marie Dröes, Stefan Sävenstedt, Birgitta Bergvall-Kåreborn, and AnnaLena Andersson. 2010. Identifying User Needs and the Participative Design Process. In Supporting People with Dementia Using Pervasive Health Technologies, Maurice D Mulvenna and Chris D Nugent (eds.). Springer-Verlag London Limited, 79-100.

54. Harry R. Moody. 1993. Overview: What is Critical Gerontology and Why Is It Important. In Voices and Visions of Aging: Towards a Critical Gerontology, Robert Kastenbaum and Susan J Eklund (eds.). vii-xi.

55. Kellie Morrissey and John Mccarthy. 2015. Creative and Opportunistic Use of Everyday Music Technologies in a Dementia Care Unit. Proceedings of the 2015 ACM SIGCHI Conference on Creativity and Cognition (C\&C '15), 295-298.

56. Kellie Morrissey, Gavin Wood, David Green, Nadia Pantidi, and John Mccarthy. 2016. "I'm a rambler, I'm a gambler, I'm a long way from home': The Place of Props, Music, and Design in Dementia Care. Proceedings of the 2016 ACM Conference on Designing Interactive Systems (DIS '16): 1008-1020.

57. Michael J. Muller. 1993. PICTIVE: Democratizing the Dynamics of the Design Session. In Participatory Design: Principles and Practices, Doughlas Schuler and Aki Namioka (eds.). Lawrence Erlbaum Associates, Inc.

58. Rafael Núñez and Walter J Freeman (eds.). 1999. Reclaiming cognition: the primacy of action, intention and emotion. Imprint Academic, Thorverton, UK. Retrieved from http://books.google.com/books?id=G01LhJnzUW MC

59. Deborah O'Connor, Alison Phinney, and Wendy Hulko. 2010. Dementia at the Intersections: A unique case study exploring social location. Journal of Aging Studies 24, 1: 30-39. http://doi.org/10.1016/j.jaging.2008.08.001

60. Roger Orpwood, Sidsel Bjørneby, Inger Hagen, Outi Mäki, Richard Faulkner, and Päivi Topo. 2004. User Involvement in Dementia Product Development. Dementia 3, 3: 263-279. http://doi.org/10.1177/1471301204045160

61. Jonathan Parker. 2005. Constructing Dementia and Dementia Care: Daily Practices in a Day Care Setting. Journal of Social Work 5, 3: 261-278. http://doi.org/10.1177/1468017305058935

62. Hester Parr. 2006. Mental health, the arts and belongings. Transactions of the Institute of British Geographers 31, 2: 150-166. http://doi.org/10.1111/j.1475-5661.2006.00207.x

63. T Perrin. 1997. Occupational need in severe dementia: a descriptive study. Journal of advanced nursing 25, 5: 934-41.

http://doi.org/10.1046/j.1365-

2648.1997.1997025934.x

64. Tessa Perrin. 1997. The Positive Response Schedule for Severe Dementia. Aging \& mental health 1, 2: 184-191. http://doi.org/10.1080/13607869757290

65. Yvonne Rogers and Gary Marsden. 2013. Does he take sugar? Moving beyond the rhetoric of compassion. interactions 20, 4: 48-57. http://doi.org/10.1145/2486227.2486238

66. Yvonne Rogers, Jeni Paay, Margot Brereton, Kate Vaisutis, Gary Marsden, and Frank Vetere. 2014. Never Too Old: Engaging Retired People Inventing the Future with MaKey MaKey. Proceedings of the SIGCHI Conference on Human Factors in Computing Systems (CHI '14), ACM Press, 39133922.

67. Julia Rozanova. 2010. Discourse of successful aging in The Globe \& Mail: Insights from critical gerontology. Journal of Aging Studies 24, 4: 213222. http://doi.org/10.1016/j.jaging.2010.05.001

68. Steven R Sabat. 2006. Implicit memory and people with Alzheimer's disease: Implications for caregiving. American Journal of Alzheimer's Disease and Other Dementias 21, 1: 11-14. http://doi.org/10.1177/153331750602100113

69. Steven R Sabat, Ann Johnson, Caroline Swarbrick, and John Keady. 2011. The "demented other" or simply "a person"? Extending the philosophical discourse of Naue and Kroll through the situated self. Nursing Philosophy 12: 282-292.

70. Carol Bowlby Sifton. 2000. Maximizing the 
Functional Abilities of Persons with Alzheimer's Disease and Related Dementias. In Interventions in Dementia Care: Toward Improving Quality of Life. Springer Publishing Company, New York, New York, 11-37.

71. Carol Bowlby Sifton. 2000. Well-Being and Doing: Enabling Occupation with Persons with Dementia. Alzheimer's Care Quarterly 1, 2: 7-28.

72. Gwi-Ryung Son, Barbara Therrien, and Ann Whall. 2002. Implicit Memory and Familiarity Among Elders with Dementia. Journal of Nursing Scholarship 34, 3: 263-267. http://doi.org/10.1111/j.1547-5069.2002.00263.x

73. Lucy A. Suchman. 1987. Plans and situated actions: the problem of human-machine communication. Cambridge University Press, New York.

74. Janelle S. Taylor. 2008. On Recognition, Caring, and Dementia. Medical Anthropology Quarterly 22, 4: 313-335. http://doi.org/10.1111/j.15481387.2008.00036.x

75. John Vines, Rachel Clarke, Peter Wright, John McCarthy, and Patrick Olivier. 2013. Configuring participation: on how we involve people in design. Proceedings of the SIGCHI Conference on Human Factors in Computing Systems (CHI '13), ACM Press, 429-438. http://doi.org/10.1016/S0142694X(98)00026-X

76. John Vines, Gary Pritchard, Peter Wright, Patrick Olivier, and Katie Brittain. 2015. An Age-Old Problem : Examining the Discourses of Ageing in $\mathrm{HCI}$ and Strategies for Future Research. $A C M$ Transactions on Computer-Human Interaction 22, 1.
77. Jayne Wallace, Anja Thieme, Gavin Wood, Guy Schofield, and Patrick Olivier. 2012. Enabling self, intimacy and a sense of home in dementia: An Enquiry into Design in a Hospital Setting. Proceedings of the SIGCHI Conference on Human Factors in Computing Systems (CHI '12), ACM Press, 2629-2638. http://doi.org/10.1145/2207676.2208654

78. Jayne Wallace, Peter C. Wright, John McCarthy, David Philip Green, James Thomas, and Patrick Olivier. 2013. A design-led inquiry into personhood in dementia. Proceedings of the SIGCHI Conference on Human Factors in Computing Systems (CHI '13), ACM Press, 26172626. http://doi.org/10.1145/2470654.2481363

79. Rupert Wegerif and Yang Yang. 2011. Technology and Dialogic Space: Lessons from History and from the "Argunaut" and "Metafora" Projects. Connecting Computer-Supported Collaborative Learning to Policy and Practice: CSCL2011 Conference Proceedings.

80. Terry Winograd and Fernando Flores. 1986. Understanding Computers and Cognition: A New Foundation for Design. Ablex Publishing Corporaton.

81. Peter Wright and John McCarthy. 2008. Empathy and experience in HCI. Proceedings of the SIGCHI Conference on Human Factors in Computing Systems (CHI '08): 637-646. http://doi.org/10.1145/1357054.1357156

82. Livescribe Sound Stickers. http://store.livescribe.com/sound-stickers-1-1.html. 